\title{
SUBJETIVIDADE E MUNDO: UMA COMPARAÇÃO ENTRE FERNANDO PESSOA E EUGÉNIO DE ANDRADE
}

Joana Souto Guimarães Araújo ${ }^{1}$

\section{Resumo}

A identificação do eu-empírico com o eu-poético caracteriza o gênero lírico, e a tensão entre ambos na poesia esteve desde sempre presente. Na poesia moderna nota-se constantemente este conflito localizado no afastamento entre essas duas instâncias do indivíduo. Atribui-se o caso, sobretudo, ao questionamento do eu diante da crise do sujeito institucional no período moderno. Nosso artigo propõe uma comparação entre poemas de dois expoentes da literatura moderna portuguesa, Fernando Pessoa e Eugénio de Andrade, com o objetivo de verificar as manifestações dessa questão, muitas vezes denominada "despersonalização da poesia" ou "apagamento da subjetividade". Através de breve recorte, procuramos observar as diferentes soluções dadas por esses autores para as contradições latentes entre o problema da autoria e suas relações com a obra e o mundo.

Palavras-chave: eu-empírico, eu poético, autoria, Modernidade

\begin{abstract}
One of the most significant characteristics of the lyric genre is the identification of the empirical with the poetic subject. The tension between both has been constant throughout poetry history, but within modern poetry, the conflict has been resolved through their divorce. This article aims at comparing briefly two exponents of Modern Portuguese Poetry, Fernando Pessoa and Eugénio de Andrade, so as to examine the manifestations of the so-called "despersonalization" of poetry. Our intention is to observe the different solutions given by these authors to the latent contradictions among authorship, art and the world.
\end{abstract}

Key words: empirical subject, poetic subject, authorship, Modernity

Falar é o modo mais simples de nos tornarmos desconhecidos. (PESSOA, 1994, p. 140)

O exame que pretendemos, da relação entre subjetividade e mundo em dois momentos do pensamento poético moderno português, impõe-nos, invariavelmente, o retorno, ainda que breve, às matrizes filosóficas do Romantismo, constituídas principalmente por obras como a Metafísica do espírito de Fichte e a Metafísica da Natureza de Schelling, ambas determinantes da visão romântica de mundo subjacente à episteme moderna, conforme aponta Benedito Nunes em "A visão Romântica"

\footnotetext{
${ }^{1}$ Mestranda em Literatura Portuguesa pelo Departamento de Letras Clássicas e Vernáculas da Faculdade de Filosofia, Letras e Ciências Sociais da Universidade de São Paulo. Bolsista da FAPESP.
} 


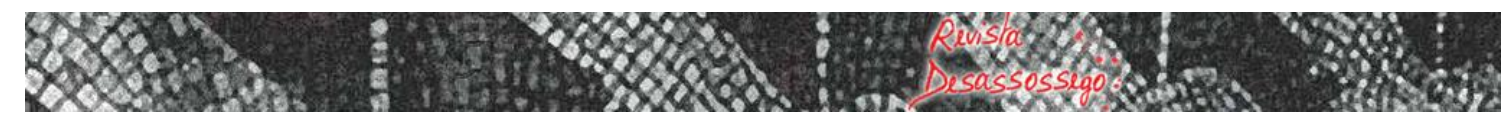

(NUNES, 1978, pp. 51-74). Ligada à "afirmação do indivíduo" e ao "conhecimento da natureza", a visão de mundo romântica firmou-se entre as duas décadas finais do século XVIII e a primeira metade do século XIX, e representou uma ruptura em relação à visão clássica em torno do binômio homem e natureza, participantes ambos, segundo Nunes, de um "prévio circuito de comunicação" que abarcava todos os seres vivos.

As novas concepções da natureza - as quais, desde o século XVII, foram deixando de se referir apenas ao mundo exterior para sugerir também o âmbito dos instintos, dos sentimentos, das "explosões emocionais que desmancham de todo a clara linha da Razão" (PEIXOTO, 1999, p. 65) $\square-$, aliadas ao culto do eu durante o período romântico, circunscreveram o "individualismo egocêntrico" que substituiu o "individualismo racionalista" clássico em que o homem era parte do universo ordenado. As idéias fichteanas acerca da liberdade, da originalidade e da espontaneidade do eu criador, "capaz de se autodeterminar e determinar ao mesmo tempo o mundo exterior" (PEIXOTO, 1999, p. 122), provocaram um avultamento do sujeito, o qual, por conseguinte, passou a ter uma vivência contraditória da natureza: se o homem enxergava a si mesmo em continuidade com o mundo natural, espaço de quietude, comunhão e consolo às mazelas da existência, ele percebia-se também cindido pelo próprio ato de pensar, que o isolava do universo instintivo da natureza. $\mathrm{O}$ homem sentia-se, portanto, como um ser pertencente a duas esferas: a da natureza e a da razão, e inaugurava-se, assim, o confronto dramático entre o indivíduo e o mundo, que, acompanhado do sentimento de falta e nostalgia em torno da perda da totalidade orgânica vivenciada pelos antigos, persistiu ao longo da Modernidade.

Os pensadores do Romantismo, ao proporem a revisão das poéticas e dos preceitos clássicos em torno da arte, ainda deslocaram o foco da relação clássica (de imitação) entre obra e natureza, para concentrarem-se na tríade artista, obra e natureza, alterando o estatuto da arte e a situação do poeta, familiares até os dias de hoje:

Por intermédio da visão romântica [...] é que surge [...] essa autonomia intelectual dilemática da consciência artística, ora cultivada em altivo isolamento, ora trazida a publico, em cumprimento de um dever apostólico, de uma missão espontânea para com a arte [...]; e é nela que entramam a obra de arte e o estado do mundo, colocando aquela num permanente confronto com o real. (NUNES, 1978, p. 54) 


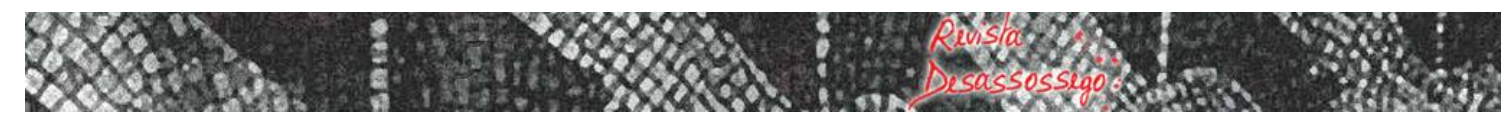

A poesia escrita a partir de então passou a expressar cada vez mais a preocupação perante seu próprio fazer poético e papel no mundo. A obra de arte deveria realizar, mediante a interferência crítica do artista e seu ato divino de criação, o vínculo entre o eu e a natureza, aspirando, desse modo, ao infinito: "O eu alcança na obra de arte a intuição de si mesmo como Absoluto" (NUNES, 1978, p. 61). Porém, o próprio fazer poético revelou-se limitado e fracassado diante do transcendente ou do absoluto. Nem o artista e nem a arte existiam na totalidade. $\mathrm{O}$ artista romântico viu-se obrigado a enfrentar o caos da vida, da arte e do mundo, e sua sensibilidade conflitiva transmutouse num forte sentimento de ironia, definido por Schlegel como "Consciência clara da eterna agilidade, do caos infinitamente pleno", que veio se identificar "com a infinitude do desejo insatisfeito" (NUNES, 1978, p. 68), e constituir, desse modo, o cerne da problemática romântica e um dos principais legados à modernidade. Embora tal questão tenha tomado rumos diversos, como se pretende demonstrar, muito da relação entre sujeito e mundo problematizada na poesia moderna pôde partir da negação romântica:

O dilaceramento da consciência individual, socialmente bloqueada, que se introverte e se afirma como a potência interior infrangível do Eu, negando o mundo que a nega, enxertou-se, com o afã de totalidade e de integridade em que o individualismo egocêntrico se externou, no culto da natureza. (NUNES, 1978, p. 69)

A decomposição do eu será um tema recorrente na Modernidade após o fracasso do homem diante do transcendente e a posterior proclamação da "morte de Deus", durante a virada entre os séculos XIX e XX, momento em que se tornou possível questionar os postulados basilares do pensamento ocidental. A crise do sujeito, iniciada séculos antes, encontrou-se ainda mais ampliada com a dissolução das verdades absolutas: o senso de identidade e a unidade de consciência ruíram.

No âmbito da literatura, essas transformações vieram pôr em cheque a relação tradicional entre autor e agente do discurso, conforme atesta Ettore Finazzi Agro, em $O$ Alibi Infinito. Através da extinção contínua da própria personalidade do autor, o caráter ficcional do texto foi sendo posto, cada vez mais, em evidência, uma vez que, "o não conseguir-se encontrar como real, deixa atrás de si um espaço para a ficção". (AGRO, 1987, p. 34). Além disso, a ênfase nos processos de gênese textual já vinha sendo trabalhada e manifestada na própria composição poética: a inexistência de Deus elevou o estatuto do autor ao grau de criador máximo e seus processos de criação tornaram-se 
material e motivação da expressão artística.

$\mathrm{Na}$ literatura portuguesa, Fernando Pessoa discutiu a ficcionalidade da emoção poética em seu poema “Autopsicografia” (PESSOA, 1980, p. 104), problematizando, ainda, a autoria na criação de seus heterônimos. Embora realizados de maneira bastante distinta, é nesse contexto de continuidade que gostaríamos também de inserir os poemas aqui selecionados de Eugênio de Andrade, poeta que tem sido situado pela tradição crítica portuguesa, juntamente com a poesia de Sophia Andresen, Jorge de Sena, Cinatti e Tomaz Kin, como uma reação ao movimento de Presença, conforme explica José Bento:

[Eugénio de Andrade] faz do poema um acontecimento de linguagem e não documento ou depoimento humano. [...] O poeta deixa de chamar a atenção para si próprio, para sua biografia, para exigir uma atenção total para o poema: só neste ele terá uma existência que interessa aos outros [...]. (BENTO, 1971, p. 307)

Ambos os poetas, embora de maneiras diversas, trabalharam a questão da chamada "despersonalização" ou "apagamento da subjetividade" na poesia. Nas páginas seguintes, pretendemos realizar uma comparação entre seus poemas, com o objetivo de analisar algumas das soluções propostas por esses autores para as contradições entre sujeito, obra e mundo.

\section{O poema no mundo}

Os poemas reproduzidos abaixo discorrem sobre seu próprio percurso e recepção no mundo. O primeiro pertence ao ciclo "O guardador de rebanhos" escrito em 1914 pelo heterônimo "mestre" Alberto Caeiro:

\section{Poema XLVII}

Da mais alta janela da minha casa

Com um lenço branco digo adeus

Aos meus versos que partem para a Humanidade.

E não estou alegre nem triste.

Esse é o destino dos versos.

Escrevi-os e devo mostrá-los a todos

Porque não posso fazer o contrário

Como a flor não pode esconder a cor,

Nem o rio esconder que corre,

Nem a árvore esconder que dá fruto. 
Ei-los que vão já longe como que na diligência

E eu sem querer sinto pena

Como uma dor no corpo.

Quem sabe quem os lerá?

Quem sabe a que mãos irão?

Flor, colheu-me o meu destino para os olhos.

Árvore, arrancaram-me os frutos para as bocas.

Rio, o destino da minha água era não ficar em mim.

Submeto-me e sinto-me quase alegre,

Quase alegre como quem se cansa de estar triste.

Ide, ide de mim!

Passa a árvore e fica dispersa pela Natureza.

Murcha a flor e o seu pó dura sempre.

Corre o rio e entra no mar e a sua água é sempre a que foi sua.

Passo e fico, como o Universo.

(PESSOA, 1980, p. 164)

Nossa opção por um poema de Caeiro pode ser justificada pelo fato de o "nascimento" deste primeiro heterônimo no "Dia triunfal" ter dado origem e impulso ao jogo heteronímico, reverberado entre os demais participantes: Ricardo Reis, Álvaro de Campos, e o ortônimo Fernando Pessoa. Vale a pena lembrar que os heterônimos não são personagens de um drama, mas os próprios textos do autor: "unidades significantes do discurso poético", de modo que se reduzem "ao estado de palavras (de frases, às vezes) que, como as que são inseridas nos textos, servem ao poeta para declarar [...] e para ocultar o seu drama de divisão" (AGRO, 1987, p. 39). É o próprio texto, portanto, que lhes dá forma, lhes atribui uma voz e uma personalidade. A vida dos heterônimos não é anterior, mas animada na malha das palavras. $O$ jogo do qual participam constituise no próprio ato poético de Fernando Pessoa.

Se, por um lado, as motivações que levaram o autor Fernando Pessoa à criação dos heterônimos são vastas e complexas, o projeto que deu vida a Alberto Caeiro, por outro, pretende-se simples e claro - principalmente quando referido pelo próprio mestre, que, de maneira quase obsessiva, defende em seus poemas a "espontaneidade" e a "objetividade" como caminhos para abandonar as contradições do pensar e fundir-se à natureza. Contudo, se tal projeto só pode ser realizado textualmente, não é incomum 
vermos contradita nos poemas a almejada simplicidade. Assim, Caeiro declara, num primeiro momento do poema acima, não estar nem "alegre nem triste" com a partida de seus versos. Essas emoções, demasiadamente espontâneas e diretas, não pertencem à sua existência discursiva. Seu estado, mais complexo, é descrito adiante como "quase alegre como quem se cansa de estar triste": paradoxo que implica a relação textual entre o autor Pessoa e o sujeito Caeiro, entre a emoção sentida e a emoção forjada, e pressupõe uma intricada rede de ligações entre o fazer poético, a natureza (o real) e o problema da personalidade. Se tanto Caeiro como os outros heterônimos foram gerados como propostas para, se não solucionar, ao menos expor as contradições vividas pelo poeta, o poema erguido na voz de Caeiro também pretende, por sua vez, fluir o "eu" cansado "de estar triste" ("Ide, ide de mim") para dispersar-se e paradoxalmente firmarse, "como o universo".

Para despedir-se de seu poema, logo no primeiro verso, o sujeito fala de um lugar elevado: "Da mais alta janela da minha casa", que muito se assemelha à "torre de marfim" dos poetas pós-românticos, os quais, em atitude convencional e literária, cantavam a partir de uma posição isolada e superior em relação às coisas mundanas. Em atitude semelhante, Alberto Caeiro revela um vasto universo interior que intenta, constantemente, a união total com as coisas em seu estado puro de natureza, afastadas, portanto, do mundo dos homens. É a partir desta aspiração que escreve seus poemas e afirma que o brotar de seus versos, assim como o destino a eles reservado, é natural como a flor que mostra a cor, o rio que corre, e a árvore que dá frutos. Porém, logo em seguida, na palavra "diligência", com a qual seus versos "já vão longe", contradiz a idéia de naturalidade antes colocada, já que os poemas executam minuciosamente o seu percurso.

No estado de natureza, os versos brotam em harmonia, porém, no momento em que partem em direção à cultura, a pureza é de certa maneira violada, como os frutos "arrancados às bocas", ou as "flor" colhida "aos olhos": comparação que sugere a tomada à força dos elementos da natureza por uma humanidade devoradora e inquieta. A recepção dos poemas parece causar angústia ao sujeito que se pergunta: "Quem sabe quem os lerá?/ Quem sabe a que mãos irão?”. Dessa maneira, Caeiro luta obsessivamente em "O guardador de rebanhos" contra a separação entre o homem e a natureza, mas a distância parece se alargar perante a dúvida em relação ao destino de 
seus versos, já que a própria existência do poema revela o desajuste e o isolamento do sujeito em relação à natureza e a toda origem.

Por conseguinte, é na "recusa do pensar pensando" que reside a ironia de Caeiro. É saber-se já separado da natureza quando se intenta colar-se ao mundo natural. Os versos partem em direção contrária a seu ímpeto inicial, que buscava completude na comunhão com os elementos. A passagem à cultura é dolorida e é também aniquiladora: pressupõe a dissolução de seu próprio eu que se esforçara para recompor-se na plenitude com a natureza: "passa a árvore"; "murcha a flor"; "corre o rio e entra no mar". Ainda assim, contra a ausência de sentido e perecimento, o poema resiste: "fica dispersa pela natureza"; "seu pó dura sempre"; "entra no mar e a sua água é sempre a que foi sua". A poesia realiza o movimento do eterno retorno: "Passo e fico, como o Universo". Embora o poema implique a morte, já que executa a transferência de um estado ao outro, gerando transformação, ele aspira à permanência por meio de seu ciclo metamórfico. O sujeito adquire condição de permanência no fluir do texto.

Os demais heterônimos têm Caeiro como mestre, pois ele é peça principal no projeto Pessoano de recomposição de um eu fragmentado à plenitude mítica do ser. Conforme aponta Octávio Paz, "Caeiro é a única afirmação que Pessoa fez": representa o mito do poeta inocente; "é o silêncio que fundamenta e sustenta" as obras de seus discípulos heterônimos:

O poeta inocente não necessita nomear as coisas; as suas palavras são árvores, nuvens, aranhas, lagartixas [...]. O poeta real sabe que as palavras e as coisas não são o mesmo, e por isso, para restabelecer uma precária unidade entre o Homem e o Mundo, nomeia as coisas com imagens, ritmos, símbolos e comparações. As palavras não são as coisas: são as pontes que desdobramos entre elas e nós [...]. As opacas palavras do poeta real evocam a fala de antes da linguagem, o entrevisto acordo paradisíaco. Fala inocente: silêncio em que nada se diz porque tudo está dito, tudo se está dizendo [...]. (PAZ, 1983, p. 25)

Ao mesmo tempo que afirma, a poesia de Caeiro nega seu próprio dizer. Suas palavras são pronunciadas somente para sussurrarem um silêncio primordial. Em "Espera" de Eugênio de Andrade, pertencente ao livro As mãos e os frutos, de 1948, o silêncio também é o destino do poema:

\section{Espera}


Aqui onde o exílio

dói como agulhas fundas, esperarei por ti

até que todas as coisas sejam mudas.

Até que uma pedra irrompa

E floresça.

Até que um pássaro me saia da garganta

E no silêncio desapareça.

(ANDRADE, 1966, p. 50)

O poema parte de uma situação inicial em que o sujeito lamenta o "exílio" de si mesmo e do mundo: "as coisas" ao redor se emudecem, e o indivíduo enfrenta a condição dolorosa de isolamento e paralisia. Diante desse quadro, o sujeito poético se rebela e procura pelo cantar - metaforizado na imagem "Até que um pássaro me saia da garganta" - expressando confiança na linguagem poética e na chegada do "tu" como capazes de reinstituir a plenitude. Sua voz angustiada gradualmente consubstancia-se na linguagem do poema, posta em movimento, a tomar as rédeas, movendo os desejos, a percepção e a imaginação de modo a multiplicar metamorficamente as imagens. $\mathrm{O}$ recurso da analogia e da aproximação de elementos díspares, como "pedra que floresce", também evoca o pensamento mágico e permite certo prolongamento mítico das palavras, restituindo a sensação de simultaneidade e de reversibilidade do tempo, por meio do nexo firmado entre coisas aparentemente longínquas. Pressente-se a reinstauração da unidade perdida entre homem e mundo, ainda que ela se revele frágil ao final do poema, com o retorno do "silêncio", destino que, embora bastante aspirado por essa poesia - a palavra poética em outro poema é referida como "morada do silêncio" 2 -, aqui parece envolto em melancolia, o que poderia sugerir a temporariedade do canto e o retorno da condição de esterilidade inicial.

Eugénio de Andrade expõe ao leitor as etapas poéticas, a fim de incitá-lo a percorrer o espaço do poema e reconhecer suas forças latentes, as potencialidades infinitas do desejo e da imaginação que libertam o sujeito de sua existência confinada nos modos de vida e padrões sociais dominantes. O poeta procura revelar os materiais brutos do poético, aludidos pela metáfora da "pedra" que "irrompe" e "floresce", bem como as formas elementares e os processos constitutivos do poema, refazendo os caminhos de

\footnotetext{
${ }^{2}$ Verso de Eugénio de Andrade citado por Luís Miguel Nava, em O essencial sobre Eugénio de Andrade, Maia: Imprensa Nacional - Casa da Moeda, 1987, p. 51.
} 
sua própria gênese, desde suas motivações iniciais, como o impulso lírico-amoroso, até o próprio trabalho das imagens.

Ave, assim como barco, cristal, fonte e casa, é signo que, na sua recorrência na obra de Eugênio de Andrade, pode ser lido como palavra, canto, poesia, a qual, neste poema, retorna ao "silêncio", encerrando o ciclo de seu eterno nascimento e transmutação. Uma leitura possível para "ave" seria a de que ela é uma representação arquetípica da forma, ou da materialidade "absoluta" da poesia. Pássaro a voar em direção a um horizonte em expansão poderia figurar o abrir para o absoluto que qualquer estrutura rítmica aspira, tanto na poesia quanto nos rituais antigos, em que o ritmo, a dança e a reza ensaiavam re-ligação do homem com o Universo. Assim como no poema de Caeiro, o poema aspira à transcendência e re-ligação com o ser original.

O silêncio, contudo, em que acaba o poema de Eugênio, é ambíguo: por um lado, poderia implicar a totalidade original e paradisíaca a que o poeta aspira, e por outro, expressa a impotência e a fragmentação do sujeito moderno. Assim, o traçado da poesia é amplo, mas ironicamente se revela curto demais, pois retorna ao seu estado de mudez e pedra que o poeta deverá lapidar com o esforço e paciência de quem espera por completude.

A problematização da autoria, a tensão entre o eu empírico e o eu poético presente principalmente nos motivos amorosos, e a insaciabilidade de um eu cindido à procura de um tu são questões presentes na poesia de Eugénio de Andrade, relativas à subjetividade manifestada na lírica em contato com o mundo. Geralmente, essas contradições são resolvidas, nesta poesia, na própria linguagem, que, em movimento de emancipação, gradualmente apaga as marcas do eu para evidenciar a potencialidade verbal e material da expressão. Horizontes em expansão, como a abertura imagética do poema acima, que decompõe a figura inicial do sujeito, ampliando-se muito além de "sua garganta" e de seu esperar desesperado, são constantes nesta poesia, assim como a apreensão do mundo substancial, animado pelas capacidades rítmicas e imagéticas da linguagem.

Dessa maneira, a própria forma, como afirma Michael Hamburger, também assume o papel de máscara. A prática significante anula a presença do autor que fala, pois chama a atenção para o lugar do texto, espaço em que ocorre "a destruição de toda voz e de toda origem", conforme também explicou Barthes (1988, p. 65). O autor se esconde 
para deixar que a linguagem tome voz:

O equilíbrio exato entre a expressão do sentimento e a penetração do mundo exterior talvez seja um problema para os poetas quando não estão escrevendo poesia [...]. Quando o poema é bemsucedido, o problema se acha resolvido nele: em seus limites, uma correspondência mágica. (HAMBURGER, 2007, p. 48)

A ironia, o jogo heteronímico e a ênfase na linguagem são maneiras de se criar máscaras e lidar com as contradições vivenciadas pelo eu empírico em contato com a realidade exterior. As formas poéticas resistem ao dilaceramento e ao esvaziamento do sujeito, cada vez maior no mundo moderno.

No entanto, todo empenho poético alcança o lugar inesperado onde a palavra não só afirma, mas também nega: ponto de coincidência entre o cantar e o silêncio, entre nascimento e morte. Ainda que o poeta consiga construir um texto autônomo, que se desprenda, capaz de expandir-se e resignificar o próprio eu, a tensão entre o eu empírico e o eu poético está sempre latente.

Assim, a poesia de Eugénio de Andrade também expressa, frequentemente, o sentimento de impotência e insuficiência em relação à linguagem como resistência às contradições vividas pelo sujeito. Nem sempre, portanto, encontramos expressa a confiança perante as formas poéticas como capazes de transmutar a realidade em que o eu se encontra mergulhado. No poema "Serão palavras só", o poeta questiona o estatuto autônomo da linguagem:

\section{Serão palavras só ...}

Diremos prado bosque primavera, e tudo o que dissermos é só para dizermos que fomos jovens.

Diremos mãe amor um barco, e só diremos que nada há para levar ao coração.

Diremos terra ou mar ou madressilva, mas sem música no sangue serão palavras só, 


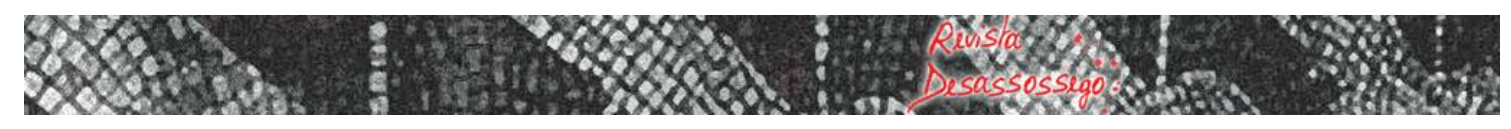

e só palavras, o que diremos.

(ANDRADE, 1966, p. 186)

No poema "Espera", assim como em boa parte da poesia eugeniana, a linguagem é explorada de modo que cumpra a ligação desejada entre o sujeito e as coisas ao redor, oferecendo-se como elo mágico. No entanto, no poema acima, o sujeito desconfia da força inerente da linguagem, capaz de instaurar uma realidade alternativa que transcenda a consciência dolorosa de si. As marcas da subjetividade, muitas vezes "apagadas" por detrás da forma, aqui reivindicam sua centralidade na motivação do poético, embora o uso da terceira pessoa do plural ainda mantenha certo distanciamento lírico. A dinâmica do jogo poemático entre as palavras, o ritmo e o sujeito poético revela-se vazia e sem sentido quando destituída do "sangue" do próprio poeta ou do leitor, ou seja, o sentir, o pensar e o imaginar dos sujeitos empíricos envolvidos no ato poético. Assim, nesse poema, através da voz lírica assumida, o poeta lamenta a velhice e o arrefecimento dos sentidos.

Nos poemas XXIX e XV de "O guardador de rebanhos", Alberto Caeiro também parece admitir certa falha em seu projeto de simplicidade e naturalidade essenciais, ao discorrer sobre a complexa rede de sentidos que o constitui e que também se revela no poema. O primeiro tem como abertura o verso "Nem sempre sou igual no que digo e escrevo" (PESSOA, 1980, p. 155), e no segundo poema, temos:

As quatro canções que seguem

Separam-se de tudo o que eu penso,

Mentem a tudo o que eu sinto,

São do contrário do que eu sou ...

Escrevi-as estando doente

E por isso elas são naturais

E concordam com aquilo que sinto,

Concordam com aquilo com que não concordam ...

Estando doente devo pensar o contrário

Do que penso quando estou são.

(Senão não estaria doente),

Devo sentir o contrário do que sinto

Quando sou eu na saúde,

Devo mentir à minha natureza

De criatura que sente de certa maneira ...

Devo ser todo doente - idéias e tudo.

Quando estou doente, não estou doente para outra cousa.

Por isso essas canções que me renegam 


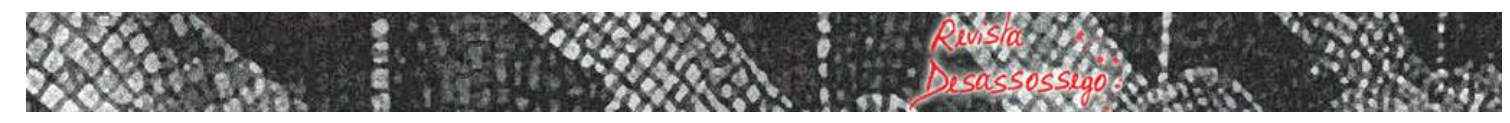

Não são capazes de me renegar

E são a paisagem da minha alma de noite,

A mesma ao contrário ...

(PESSOA, 1980, p. 149)

No que consistiria a "doença" de Caeiro senão a consciência dolorosa da negação e da separação em relação à natureza que invade o poema, não obstante a afirmação promovida pelo jogo heteronímico? A tensão, portanto, entre o sujeito lírico (Caeiro), criado para movimentar-se em direção à natureza e ao encontro do ser primordial, e o sujeito empírico (autor Pessoa), que duvida de seu próprio projeto e contradiz seu esforço de criação, revela-se presente.

O ato poético se oferece, por conseguinte, como um espaço de crítica e reflexão. $\mathrm{O}$ autor e também o leitor se projetam e se recriam por meio do texto, mas o próprio poema, uma vez forjado, exige, por sua vez, constante reconstituição, não só do eu que escreve, como também do eu que lê. Ou seja, o texto interfere na dialética do sujeito com o mundo, e sua estrutura móvel impõe novas dinâmicas e aberturas para novos significados. O poeta renova seu gesto indefinidamente, como observamos na poesia de Fernando Pessoa e Eugénio de Andrade, e o que parece contradição à primeira vista, revela-se, na análise do conjunto dos poemas, empenho crítico. A poesia moderna procura, antes de tudo, pensar-se e evidenciar ao leitor seus próprios caminhos e processos constitutivos, com o intuito de inspirá-lo a percorrer o espaço e o tempo poéticos de maneira a participar do ato de recriação que está a propor. Se as verdades e as identidades se revelam fluídas ao homem moderno, a poesia, através de sua estrutura essencialmente dinâmica, propõe constante reflexão acerca das profundas transformações.

\section{Bibliografia}

ANDRADE, Eugénio. Poemas - 1945-1965. Lisboa: Portugália, 1966.

AGRO, Ettore Finazzi. O Alibi Infinito —o projeto e a prática na poesia de Fernando Pessoa. Lisboa: Imprensa Nacional, 1987.

BARTHES, Roland. O rumor da língua. São Paulo: Editora Brasiliense, 1988.

BENTO, José. "Poemas de Eugênio de Andrade". In: 21 ensaios sobre Eugênio de Andrade. Porto: Inova, 1971.

HAMBURGER, Michael. A verdade da poesia. SP: Cosac Naify, 2007. 
NAVA, Luís Miguel. O essencial sobre Eugénio de Andrade. Maia: Imprensa Nacional - Casa da Moeda, 1987.

NUNES, Benedito. “A visão Romântica”. In: O Romantismo, org. J. Guinsburg. São Paulo: Editora Perspectiva, 1978, pp. 51 a 74.

PAZ, Octávio. Fernando Pessoa - o desconhecido de si mesmo. Lisboa: Vega, 1983.

PEIXOTO, Sérgio Alves. A consciência criadora na poesia brasileira do barroco ao simbolismo. São Paulo: Annablume, 1999.

PESSOA, Fernando. O Eu profundo e os outros eus. Rio de Janeiro: Nova Fronteira, 1980.

- "Balança de Minerva. In: Páginas sobre Literatura e Estética, organização, introdução, notas e bibliografia básica atualizada de Antonio Quadros, Portugal, Mem Martins: Publicações Europa-América Ltda., 1994. 